\title{
Dysfunctional Grief Related to COVID-19 in Latin America
}

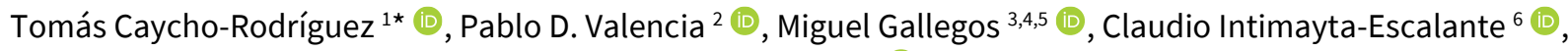 \\ Michael White ${ }^{7}$ (D)
}

\author{
${ }^{1}$ Universidad Privada del Norte, PERU \\ ${ }^{2}$ Facultad de Estudios Superiores Iztacala, Universidad Nacional Autónoma de México, MEXICO \\ ${ }^{3}$ Universidad Católica del Maule, Talca, CHILE \\ ${ }^{4}$ Pontificia Universidade Católica de Minas Gerais, BRAZIL \\ ${ }^{5}$ Consejo Nacional de Investigaciones Científicas y Técnicas, ARGENTINA \\ ${ }^{6}$ Sociedad Científica de San Fernando (SCSF), Lima, PERU \\ ${ }^{7}$ Facultad de Ciencias Humanas y Educación, Universidad Peruana Unión, Lima, PERU \\ *Corresponding Author: tomas.caycho@upn.pe
}

Citation: Caycho-Rodríguez T, Valencia PD, Gallegos M, Intimayta-Escalante C, White M. Dysfunctional Grief Related to CoVID-19 in Latin America. Electron J Gen Med. 2022;19(2):em344. https://doi.org/10.29333/ejgm/11543

\begin{tabular}{|c|c|}
\hline ARTICLE INFO & ABSTRACT \\
\hline Received: 7 Oct. 2021 & associated with COVID-19-related dysfunctional grief suggest that we are most likely facing \\
\hline Accepted: 23 Dec. 2021 & $\begin{array}{l}\text { "dysfunctional grief pandemic" due to COVID-19. Thus this preliminary study reports frequencies of dysfunctional } \\
\text { grief in ten Latin American countries that varied between } 7.3 \% \text { in Brazil and } 14.6 \% \text { in El Salvador. This highlights a } \\
\text { greater need for Latin American countries to work together to improve the accessibility of treatment for } \\
\text { dysfunctional grief. }\end{array}$ \\
\hline
\end{tabular}

Keywords: COVID-19, dysfunctional grief, Latin America

Dear Editor,

Latin America is one of the regions most affected by COVID19, with more than 43.8 million confirmed cases as of September 10, 2021, with Brazil being the most affected country with more than 21 million confirmed cases. Similarly, as of the same date, more than 1.4 million people have died from COVID-19 in the region, with Brazil and Mexico being the most affected countries, with 585,174 and 266,150 deaths from COVID-19, respectively. This reality has led Latin American countries, like others in the world, to focus their efforts on mitigating the spread and mortality of COVID-19. However, little attention has been paid to the mental health consequences of the pandemic, such as the bereavement, or grief, of people who have suffered the death of a loved one from COVID-19. Bereavement is a natural process that manifests as a painful emotional response to the loss of a loved one and is present in all human cultures [1]. However, when there is an inability to cope with this process, excessive levels of grief negatively impact family, work and social relationships, even several months after the loss of the loved one becoming a psychiatric problem [2]. The dysfunctional grief experience generates risks for physical and mental health, such as the occurrence of cardiovascular problems, addictions, anxiety, depression and suicide [3]. This leads us to consider dysfunctional bereavement as a public health problem in the context of COVID-19.

Characteristics associated with dysfunctional grief related to COVID-19, such as "grief overload" due to increased deaths of family and friends, as well as restrictions limiting interaction with relatives or loved ones in hospitals or intensive care units and performing funeral ceremonies, can lead to inadequate coping with grief and increased feelings of guilt [4]. In this context, it is estimated that the death of one person due to COVID-19 would emotionally affect approximately 9 members of a family, which would imply -according to COVID-19 related death data- about 16 million people at risk of dysfunctional bereavement worldwide [5]. These data suggest that we are most likely facing a "dysfunctional grief pandemic" due to COVID-19 [1]. Previous studies in the United States reported that between $56.6 \%$ and $66 \%$ of people who have suffered the loss of a loved one due to COVID-19 presented dysfunctional bereavement [6]. Furthermore, while bereavement is an individual experience, it is also influenced by culture-specific social norms [7]. Therefore, the way in which people experience the death of a loved one would also depend on the cultural context in which they live [8].

In this regard, a preliminary study was conducted to evaluate the presence of dysfunctional grief due to the death of a family member or loved one as a result of COVID-19 in LatinAmerican countries. This study included 2,536 people (mean age $=34.22$ years, $S D=11.99$ ) who had lost a family member or other loved ones due to COVID-19 in ten Latin-American countries (Brazil, Bolivia, Chile, Colombia, Ecuador, El Salvador, Guatemala, Mexico, Paraguay, and Peru) who were selected by non-probabilistic convenience sampling. Further information on sociodemographic data is shown in Table 1. The Spanish version of the Pandemic Grief Scale (PGS) [9], which assesses the symptoms of dysfunctional grief, was used. The PGS consists of 5 items with 4 response options, ranging from $0=$ "not at all" to $3=$ "almost every day". The total score of the PGS was obtained from the sum of the scores of each of the items and ranges from 0 to 25 , where higher values indicate a 
Table 1. Demographic information of the participants

\begin{tabular}{|c|c|c|c|c|c|c|c|c|c|c|}
\hline & $\begin{array}{l}\text { Bolivia } \\
(n=156)\end{array}$ & $\begin{array}{c}\text { Brazil } \\
(n=206)\end{array}$ & $\begin{array}{c}\text { Chile } \\
(n=179)\end{array}$ & $\begin{array}{l}\text { Colombia } \\
(n=215)\end{array}$ & $\begin{array}{l}\text { Ecuador } \\
(n=295)\end{array}$ & $\begin{array}{c}\text { El Salvador } \\
(n=437)\end{array}$ & $\begin{array}{c}\text { Guatemala } \\
(n=171)\end{array}$ & $\begin{array}{l}\text { Mexico } \\
(n=202)\end{array}$ & $\begin{array}{l}\text { Paraguay } \\
(n=441)\end{array}$ & $\begin{array}{c}\text { Peru } \\
(n=234)\end{array}$ \\
\hline \multicolumn{11}{|l|}{ Gender (\%) } \\
\hline Female & $56(35.9)$ & $49(23.8)$ & $45(25.1)$ & $69(32.1)$ & $98(33.2)$ & $167(38.2)$ & $65(38.0)$ & $80(39.6)$ & $111(25.2)$ & $68(29.1)$ \\
\hline Male & $99(63.5)$ & $157(76.2)$ & $134(74.9)$ & $146(67.9)$ & $197(66.8)$ & $268(61.3)$ & $106(62.0)$ & $120(59.4)$ & $328(74.4)$ & $166(70.9)$ \\
\hline Transgender/nonbinary & $1(0.6)$ & $0(0.0)$ & $0(0.0)$ & $0(0.0)$ & $0(0.0)$ & $2(0.5)$ & $0(0.0)$ & $2(1.0)$ & $2(0.4)$ & $0(0.0)$ \\
\hline Age $(M \pm S D)$ & $40.60 \pm 14.74$ & $35.23 \pm 10.83$ & $38.45 \pm 12.61$ & $30.65 \pm 13.04$ & $28.81 \pm 10.65$ & $29.49 \pm 9.05$ & $41.57 \pm 12.90$ & $33.89 \pm 14.22$ & $31.59 \pm 11.02$ & $31.97 \pm 10.87$ \\
\hline \multicolumn{11}{|l|}{ Marital status (\%) } \\
\hline Single & $71(45.5)$ & $108(52.4)$ & $80(44.7)$ & $154(71.6)$ & $205(69.5)$ & $315(72.1)$ & $70(40.9)$ & $113(55.9)$ & $285(64.6)$ & $147(62.8)$ \\
\hline Married & $52(33.3)$ & $57(27.7)$ & $53(29.6)$ & $35(16.3)$ & $61(20.7)$ & $79(18.1)$ & $69(40.4)$ & $70(34.6)$ & $106(24.0)$ & $51(21.8)$ \\
\hline Divorced & $21(13.5)$ & $16(7.8)$ & $16(8.9)$ & $6(2.8)$ & $18(6.1)$ & $9(2.1)$ & $15(8.8)$ & $12(5.9)$ & $14(3.2)$ & $8(3.4)$ \\
\hline Cohabiting & $7(4.49)$ & $23(11.2)$ & $27(15.1)$ & $17(7.9)$ & $7(2.4)$ & $33(7.6)$ & $12(7.0)$ & $4(2.0)$ & $33(7.5)$ & $26(11.1)$ \\
\hline Widowed & $5(3.21)$ & $2(1.0)$ & $3(1.7)$ & $3(1.4)$ & $4(1.4)$ & $1(0.2)$ & $5(2.9)$ & $3(1.5)$ & $3(0.7)$ & $2(0.9)$ \\
\hline \multicolumn{11}{|l|}{ Higher education (\%) } \\
\hline No & $7(4.5)$ & $30(14.6)$ & $12(6.7)$ & $46(21.4)$ & $53(18.0)$ & $118(27.0)$ & $16(9.4)$ & $14(6.9)$ & $51(11.6)$ & $15(6.4)$ \\
\hline Yes, technical level $^{\mathrm{a}}$ & $5(3.2)$ & $70(34.0)$ & $21(11.7)$ & $24(11.2)$ & $8(2.7)$ & $26(6.0)$ & $14(8.2)$ & $34(16.8)$ & $16(3.6)$ & $17(7.3)$ \\
\hline Yes, university level $^{a}$ & $144(92.3)$ & $106(51.5)$ & $146(81.6)$ & $145(67.4)$ & $234(79.3)$ & $293(67.0)$ & $141(82.5)$ & $154(76.2)$ & $374(84.8)$ & $202(86.3)$ \\
\hline \multicolumn{11}{|l|}{ Job type (\%) } \\
\hline Permanent & $67(43.0)$ & $135(65.5)$ & $107(59.8)$ & $71(33.0)$ & $108(36.6)$ & $221(50.6)$ & $120(70.2)$ & $94(46.5)$ & $252(57.1)$ & $92(39.3)$ \\
\hline Temporary & $35(22.4)$ & $15(7.3)$ & $23(12.8)$ & $36(16.7)$ & $46(15.6)$ & $65(14.9)$ & $28(16.4)$ & $37(18.3)$ & $69(15.6)$ & $50(21.4)$ \\
\hline Unemployed & $54(34.6)$ & $56(27.2)$ & $49(27.4)$ & $108(50.2)$ & $141(47.8)$ & $151(34.6)$ & $23(13.4)$ & $71(35.2)$ & $120(27.2)$ & 92(39.3) \\
\hline \multicolumn{11}{|l|}{ Had COVID-19 (\%) } \\
\hline Yes & $48(30.8)$ & $41(19.9)$ & $14(7.8)$ & $42(19.5)$ & $53(18.0)$ & $72(16.5)$ & $14(8.2)$ & $38(18.8)$ & $69(15.6)$ & $57(24.4)$ \\
\hline No & $82(52.6)$ & $107(51.9)$ & $151(84.4)$ & $120(55.8)$ & $187(63.4)$ & $211(48.3)$ & $136(79.5)$ & $125(61.9)$ & $283(64.2)$ & $124(53.0)$ \\
\hline Maybe yes & $17(10.9)$ & $26(12.6)$ & $7(3.9)$ & $34(15.8)$ & $33(11.2)$ & $119(27.2)$ & $12(7.0)$ & $17(8.4)$ & $50(11.3)$ & $37(15.8)$ \\
\hline Maybe no & $9(5.8)$ & $32(15.5)$ & $7(3.9)$ & $19(8.8)$ & $22(7.5)$ & $35(8.0)$ & $9(5.3)$ & $22(10.9)$ & $39(8.8)$ & $16(6.84)$ \\
\hline
\end{tabular}

aoth complete and incomplete studies were included

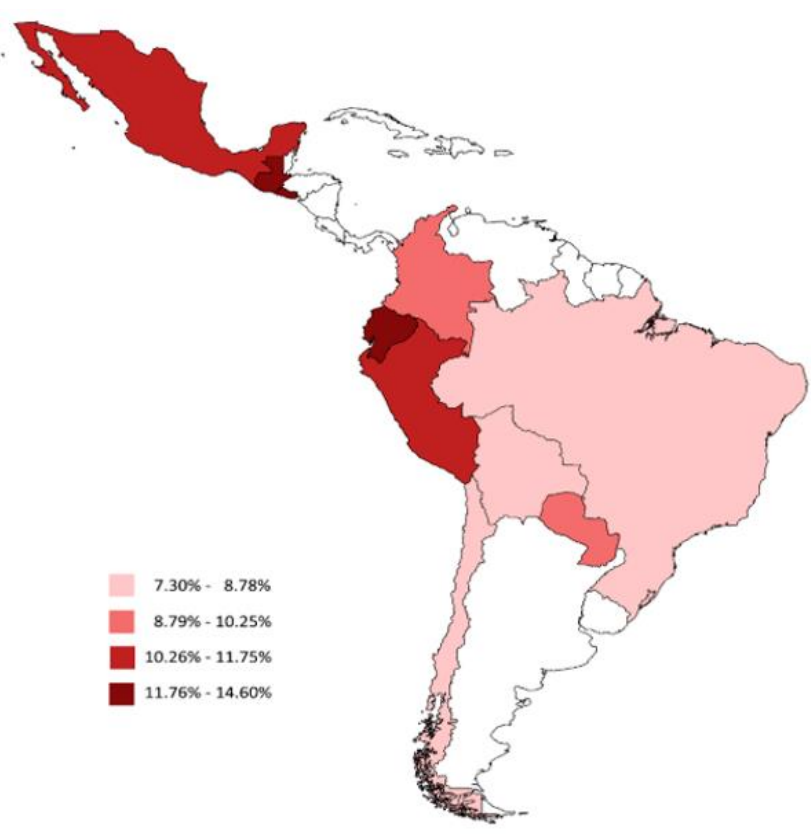

Figure 1. Frequency of dysfunctional grief related to COVID-19

higher frequency of dysfunctional grief symptoms. Furthermore, a score equal to or greater than 7 allows for adequate discrimination between people with and without COVID-19-related dysfunctional grief. The study received approval from the Ethics Committee of the Universidad Privada del Norte in Peru (registration number: 20213002). An online questionnaire was constructed using Google Forms, which included sociodemographic data, the PGS, and other additional questions. Those who reported having suffered the death of a family member or friend from COVID-19 participated. Participants gave informed consent after reading the study objectives in the online form. For this study, the calculation of frequency and percentage was used to present the data.
It was reported that El Salvador has the highest number of people with dysfunctional grief $(n=63 ; 14.6 \%)$, followed by Guatemala $(n=22 ; 12.9 \%)$, Ecuador $(n=35 ; 12.2 \%)$, Mexico $(n=21 ; 10.4 \%)$, Peru $(n=24 ; 10.3 \%)$, Paraguay $(n=44 ; 10.2 \%)$, Colombia ( $n=21 ; 10.2 \%)$, Bolivia $(n=12 ; 8.3 \%)$, Chile $(n=13 ; 7.3 \%)$, and Brazil ( $n=15 ; 7.3 \%)$ (see Figure 1). Although the results in some Latin-American countries are lower than the percentages of dysfunctional bereavement reported in the United States (between 56.6\% and 66\%) [7], there is a need for preventive interventions and emotional support for bereaved people in the region.

Preparedness to face the consequences of the pandemic on the mental health of the population varies within the region and especially among the most vulnerable countries due to the limited resources of their health systems, the higher prevalence of chronic diseases, high rates of poverty and inequality. These factors affect the impact of COVID-19 on the mental health of the population in Latin America, and also have implications for the dynamics of the pandemic in the region. In this sense, interventions against dysfunctional grief should consider its multidimensional characteristics, where individual experiences (such as the development of the meaning of death, as well as the relationships between the living and the dead) are shaped by cultural factors [10]. Thus, the emotional experience caused by the death of a loved one and the way of coping with it depends not only on the individual, but also on the cultural context in which it develops.

Attention to dysfunctional grief is probably not sufficient, since treatments are not implemented worldwide and it is possible that there are no mental health professionals adequately qualified in this problem in many communities, even more so than during the AIDS pandemic. This leads to a greater need for Latin American countries to work together to improve the accessibility of treatment for dysfunctional grief, whether provided in person or online. The latter is important; as online interventions can be delivered even if the COVID-19 pandemic lasts longer than expected. Likewise, it is not only a 
matter of providing individual responses for each family, but also of socio-community programs that aim to implement interventions.

Author contributions: TC-R, PDV, MG, CI-E and MW: Provided initial conception, organization, and main writing of the text. PDV: Analyzed the data and prepared all figures. The first draft of the manuscript was written by TC-R and all authors commented on previous versions of the manuscript. All authors read and approved the final manuscript.

Funding: No funding source is reported for this study.

Declaration of interest: No conflict of interest is declared by authors.

\section{REFERENCES}

1. Weinstock L, Dunda D, Harrington H, Nelson H. It's complicated-adolescent grief in the time of COVID-19. Front Psychiatry. 2021;12:638940. https://doi.org/10.3389/ fpsyt.2021.638940 PMid:33708148 PMCid:PMC7940762

2. Wallace CL, Wladkowski SP, Gibson A, White P. Grief during the COVID-19 pandemic: Considerations for palliative care providers. J Pain Symptom Manage. 2020;60(1):e70-6. https://doi.org/10.1016/j.jpainsymman.2020.04.012 PMid: 32298748 PMCid:PMC7153515

3. Maercker A, Neimeyer RA, Simiola V. Depression and complicated grief. In: Gold SN, editor. APA handbook of trauma psychology: Foundations in knowledge. Washington, DC: American Psychological Association; 2017:185-94 https://doi.org/10.1037/0000019-011

4. Kokou-Kpolou CK, Fernández-Alcántara $M$, Cénat JM. Prolonged grief related to COVID-19 deaths: Do we have to fear a steep rise in traumatic and disenfranchised griefs? Psychol Trauma. 2020;12(S1):S94-5. https://doi.org/ 10.1037/tra0000798 PMid:32525367
5. Tang S, Xiang Z. Who suffered most after deaths due to COVID-19? Prevalence and correlates of prolonged grief disorder in COVID-19 related bereaved adults. Global Health. 2021;17(1):1-9. https://doi.org/10.1186/s12992021-00669-5 PMid:33573673 PMCid:PMC7877329

6. Lee SA, Neimeyer RA. Pandemic grief scale: A screening tool for dysfunctional grief due to a COVID-19 loss. Death Stud. 2020;1-11. https://doi.org/10.1080/07481187.2020.1853885

7. Lund PC. Deconstructing grief: A sociological analysis of prolonged grief disorder. Soc Theory Health. 2020;1-15. https://doi.org/10.1057/s41285-020-00135-z

8. Jakoby NR. Grief as a social emotion: Theoretical perspectives. Death Stud. 2012; 36(8):679-711. https://doi.org/10.1080/07481187.2011.584013 PMid: 24563936

9. Caycho-Rodríguez T, Vilca LW, Vivanco-Vidal A, SaroliAraníbar D, Carbajal-León C, Gallegos WLA, et al. Assessment of dysfunctional grief due to death from COVID-19 in Peru: Adaptation and validation of a Spanish version of the pandemic grief scale. Trends Psychol. 2021:122. https://doi.org/10.1007/s43076-021-00091-1 PMCid: PMC8279032

10. Silverman GS, Baroiller A, Hemer SR. Culture and grief: Ethnographic perspectives on ritual, relationships and remembering. Death Stud. 2021;1-8. https://doi.org/ 10.1080/07481187.2020.1851885 PMid:33272138 